\title{
EDITORIAL
}

\section{Signal transduction pathways regulating hematopoietic stem cell biology: Introduction to a series of Spotlight Reviews}

Leukemia (2012) 26, 86-90. doi:10.1038/leu.2011.260

Hematopoietic stem cells (HSCs) have the ability to self-renew and generate all lineages of blood cells. Although it is currently well established that HSCs regenerate the blood compartment, it was only in the 1960s that the notion was introduced that multipotent progenitors can be found in the adult bone marrow (BM) and are responsible for the continuous production of blood cells throughout life. It is difficult to overestimate the influence this pioneering work, by investigators such as Metcalf, Till and McCulloch, has had on HSC biology. ${ }^{1-3}$ Since then, research from many different laboratories has contributed to the phenotypic and functional characterization of HSCs and, currently, the blood system constitutes a paradigm for understanding stem cell biology. HSCs are located at the top of a hierarchy of lineage-specific progenitors that differentiate in an ordered manner towards fully mature blood cells (Figure 1), thereby undergoing a stepwise loss of multilineage potential, and becoming progressively committed to a single hematopoietic lineage. Several evolutionarily conserved pathways, including Wnt, Notch, Hedgehog, TGF $\beta / S M A D$ and several others, regulate self-renewal, differentiation, proliferation, apoptosis and senescence of HSC. This article serves as an introductory text to a series of spotlight reviews each of which discusses one of these pathways that have been implicated in HSC biology.

\section{Hematopoietic stem cells}

HSCs are functionally defined by their ability to mediate longterm (LT) repopulation after transplantation. ${ }^{1-3}$ The strictest version of this functional definition requires that HSCs have to be re-transplantable in serial recipients, while retaining both self-renewal and multilineage differentiation capacity. ${ }^{4,5}$

In the mouse, HSCs can be found in the BM within a rare population defined by the absence of lineage-specific markers and high expression levels of stem-cell antigen 1 (Sca1) and C-Kit. Therefore, this BM subset is known as $\mathrm{Lin}^{-} \mathrm{Sca}{ }^{+} \mathrm{Kit}^{+}{ }^{+6,7}$ As only a small fraction of the $\mathrm{Lin}^{-} \mathrm{Sca}{ }^{+} \mathrm{Kit}^{+}$cells contain LT repopulating capacity, additional markers have been introduced to subdivide this heterogeneous population. LT-HSCs containing LT repopulating activity are $\mathrm{CD} 34^{-}$, fms-related tyrosine kinase 3 (Flt3) $^{-} \mathrm{CD}^{-} 8^{-}$and CD150 ${ }^{+}$. Short-term-HSCs, which have only limited repopulation capacity, are $\mathrm{CD} 34^{+}$and $\mathrm{Flt}^{-}{ }^{-}$, and multipotent progenitors that have lost self-renewal but retain multilineage differentiation potential are $\mathrm{Flt} 3^{+}$and $\mathrm{CD} 34^{+} .{ }^{8-10}$ In addition to cell surface markers, HSCs can be identified by their ability to efflux fluorescent dyes such as Hoechst 33342. This property defines a subset named side population which is highly enriched for LT-HSCs. ${ }^{11}$ The basic principles of mouse HSCs seem to also apply to human HSCs. Nevertheless, due to the lack of efficient in vivo assays, the correct definition and isolation of human HSCs has been more difficult. In humans, HSCs are enriched in the $\mathrm{Lin}^{-} \mathrm{CD} 34^{+} \mathrm{CD} 38^{-}$cells, as assessed in the SCID-repopulating cell assay. ${ }^{12,13}$ However, different studies have revealed that expression of surface markers may change depending on the developmental stage and cell cycle state of these cells. ${ }^{14}$ Studies in the mouse predict that the majority of HSCs in human cord blood and in the BM of young children are $\mathrm{CD}_{3}{ }^{+}$. Despite this, it is likely that, as in the mouse, a significant proportion of human adult HSCs do not express CD34. Thus, while CD34 selection constitutes a good method to purify human HSC from cord blood or after HSC mobilization, it may discard a sizable population of stem cells when applied to the BM of adult humans. ${ }^{14}$

\section{HSCs self-renewal and differentiation}

All stem cells are characterized by having multilineage differentiation potential on a single-cell basis, which is defined by the capacity to give rise to a differentiated progeny comprising different cell types, and by their self-renewal capacity, which allows them to replicate while preserving their broad developmental potential. Precise regulation of these two processes is essential to sustain life-long blood production and to respond to external stresses like injury or infection. ${ }^{15}$

A suitable mechanism to regulate the balance between selfrenewal and differentiation is by controlling symmetric and asymmetric cell divisions. Under homeostatic conditions, the number of stem cells in a specific tissue remains relatively constant. It is commonly assumed that this balance is probably achieved by asymmetric cell division, through which one daughter cell maintains the stem cell identity and the other becomes differentiated. This asymmetry can be achieved by unequal distribution of cytoplasmatic cell-fate determinants before cell division (divisional asymmetry). Alternatively, the two identical daughter cells can be exposed to different environmental signals after cell division, preserving stem cell fate in one daughter cell and promoting differentiation in the other (environmental asymmetry). ${ }^{16}$ These processes have been elucidated most extensively in Drosophila and Caenorhabditis elegans. Although the molecules involved are highly conserved among species, these mechanisms still remain poorly understood in mammals and more specifically in HSCs. Initial studies in the hematopoietic system suggested that hematopoietic precursors in a pro-differentiation environment tend to divide asymmetrically, whereas precursors in a pro-renewal environment preferentially divide symmetrically ${ }^{17-19}$ in order to increase the HSC pool.

Adult HSCs are mostly quiescent, with approximately $95 \%$ of them being in the G0 phase of the cell cycle. On the basis of the cycling behavior of the LT-HSCs, two populations were defined, one actively cycling and one dormant, which may constitute a reservoir of the most potent HSCs and which can be efficiently activated in response to injury. Indeed, the majority of multilineage LT activity was found in dormant LT-HSCs. ${ }^{20,21}$ Furthermore, the activation of dormant stem cells seems to be reversible, as actively cycling HSCs return to dormancy upon re-acquisition of homeostasis. ${ }^{21}$ The maintenance of a dormant pool of non-cycling and metabolically inactive HSCs was 

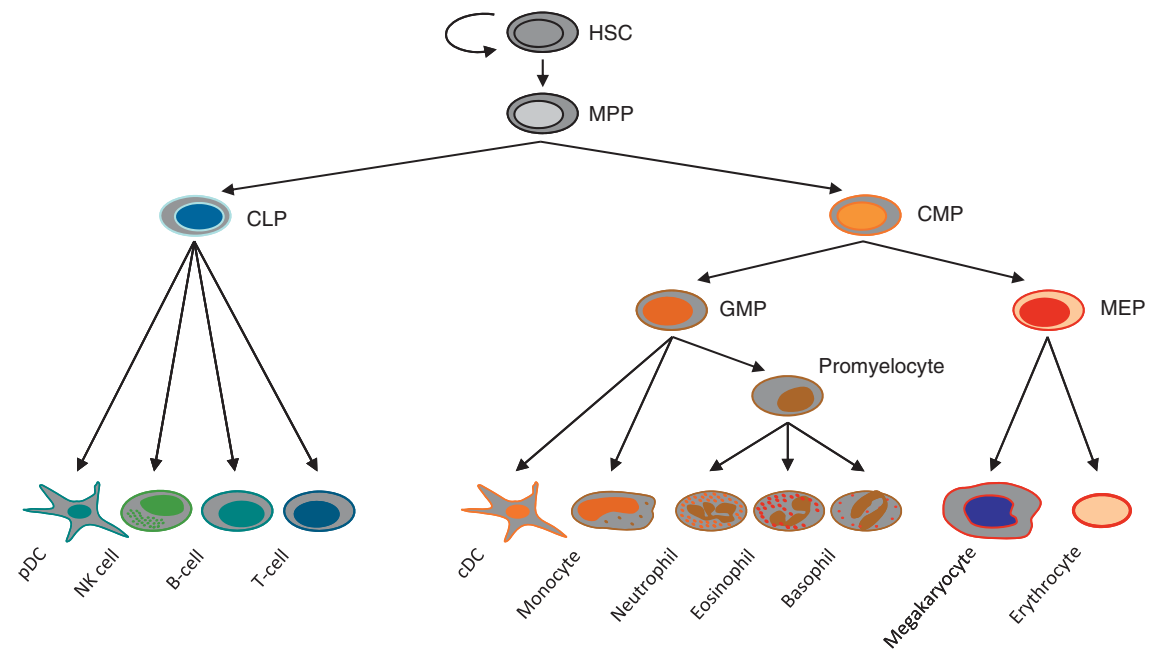

Figure 1 Schematic overview of the hematopoietic developmental hierarchy. Self-renewing HSCs reside at the top of the hierarchy, giving rise to a number of multipotent progenitors that develop into mature blood cells through a step-wise process of lineage specification and commitment. CLP, common lymphoid progenitor; CMP, common myeloid progenitor; GMP, granulocyte-monocyte progenitor; MEP, megakaryocyte-monocyte progenitor; MPP, multipotent progenitor.

suggested to be a protective mechanism against exhaustion of a limited self-renewal potential. ${ }^{15}$ In contrast to LT-HSCs, their progeny are actively cycling and are responsible for the majority of the cell expansion required for the daily production of billions of blood cells.

\section{Ontogeny of the hematopoietic system}

Blood is a mesodermally derived tissue and may have its origin in a common precursor for both endothelial and hematopoietic lineages, termed the hemangioblast. ${ }^{22-24}$ Defining the origin of the hematopoietic system is difficult because blood is a mobile tissue and hematopoietic cells emerge at different sites in the embryo and at different stages of the embryonic development, until the definitive hematopoietic organs are fully developed and ready to take over this function.

In the mouse, the first wave of hematopoiesis occurs in the extraembryonic yolk sac (YS) between embryonic days 7 (E7) and E8. This transient hematopoietic system is mainly oriented to red blood cell production. The erythrocytes produced in the YS at this stage do not get enucleated, and therefore are called primitive. Besides this, myeloid progenitors are also detected in the YS before circulation is established (E8), and are therefore generated in this location. ${ }^{25,26}$

After the first wave of primitive erythropoiesis, adult HSCs, functionally defined by their capacity to confer complete, LT and multilineage repopulation of the hematopoietic system of adult recipient mice, are first generated in the para-aortic splanchnopleura- aorta-gonads-mesonephros region and can be detected at around E10.5..$^{27,28}$ These HSCs are located in the ventral region of the dorsal aorta, in association with the endothelium wall. ${ }^{29}$ On the basis of this close proximity, it has been proposed that instead of a hemangioblast with both hematopoietic and endothelial potential, a 'hemogenic endothelium' lining the ventral aorta from which the HSCs emerge, could be the precursor of definitive HSCs. ${ }^{30-34}$ Alternatively, a third model proposed that hematopoietic precursors located in subaortic patches migrate through the mesenchyme into the dorsal aorta. ${ }^{35}$
Shortly after being generated in the aorta-gonads-mesonephros region, HSCs are detected in other tissues such as the YS, placenta and fetal liver. ${ }^{36-38}$ Whether de novo generation or only expansion of HSCs occurs in the YS and placenta is still under debate. The fetal liver does not autonomously generate HSCs. Instead, hematopoietic cells migrating from the aortagonads-mesonephros region, YS and placenta colonize the fetal liver, which becomes the major hematopoietic organ until birth when BM hematopoiesis is established. ${ }^{37,39,40}$ Analogous to the mouse embryo, hematopoietic development in the human embryo occurs in a similar manner ${ }^{41}$ (Figure 2).

\section{Fetal versus adult HSCs}

The fetal liver is the main fetal hematopoietic site for HSC expansion and differentiation. ${ }^{42}$ Although hematopoietic progenitors with myelo-erythtroid potential can be detected in the liver rudiment as early as at E9.5, the first definitive HSCs only colonize the fetal liver at around E11.5. In the liver, the HSC pool expands rapidly. Quantification of this expansion revealed a 38-fold increase in competitive repopulating units between E12 and E16. After E16, the number of repopulating units declines probably due to massive exit of HSC to either the spleen or the $\mathrm{BM}^{43}$ (Figure 2). Whereas most adult HSCs are quiescent, fetal liver HSCs are actively cycling. Besides this, the self-renewal potential of fetal liver HSCs is also higher in comparison with BM HSCs, which are outcompeted in transplantation experiments. ${ }^{44-46}$ Although this advantage can be explained by differences in the signals provided by the fetal liver and BM microenvironments, the differences in repopulation capacity observed when fetal and adult HSCs are transplanted in irradiated recipient mice also suggest the existence of inherent differences between them. ${ }^{42}$

In addition, fetal and adult HSCs vary in phenotypic and functional characterization. Contrarily to adult LT reconstituting HSCs, fetal HSCs express markers such as Mac1 (CD11b) ${ }^{45,47}$ and AA4.1 (CD97). ${ }^{48}$ Functionally, mouse fetal HSCs are able to generate $\mathrm{V} \gamma 3^{+}$and $\mathrm{V} \gamma 4^{+} \mathrm{T}$-cells in response to the fetal thymic environment, whereas adult HSCs cannot, ${ }^{49}$ and are more capable of generating B1 lymphocytes. ${ }^{50,51}$ Moreover, several 

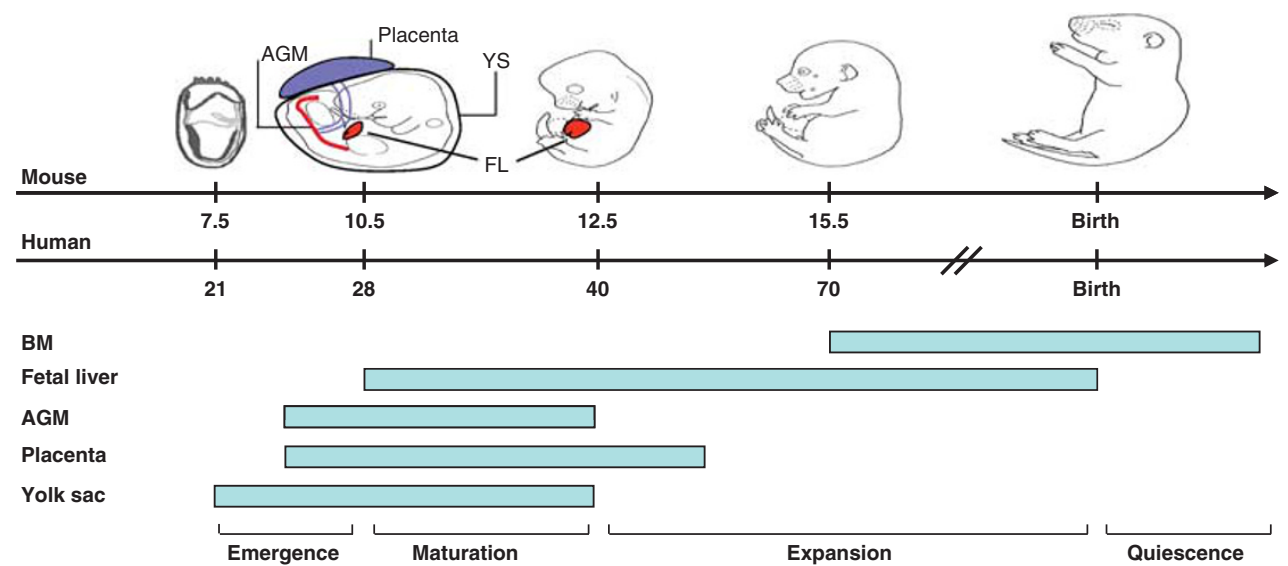

Figure 2 Establishment of definitive HSCs during embryonic development. Bars represent the ages at which mouse and human hematopoietic sites are active. FL, fetal liver; YS, yolk sac.

regulators were found to be essential for adult HSCs, such as Bmi1, Tel/Etv6 and Gfi1, but not for fetal HSCs. ${ }^{52-54}$ On the other hand, it was recently demonstrated that the transcription factor Sox 17 is required for fetal and neonatal but not adult HSC function. ${ }^{55}$ Moreover, gene-expression profiling demonstrated differences in adult versus fetal HSCs gene expression ${ }^{56,57}$ that may underlie the functional differences in adult versus fetal HSC.

In the last stages of gestation, cells start migrating to the BM. In the mouse, the transition from fetal to adult HSC properties happens 3-4 weeks after birth, when HSCs abruptly become quiescent $^{58}$ (Figure 2). The functional differences that distinguish fetal from adult HSCs may be conferred by their unique microenvironments. Nevertheless, the mechanisms underlying these modifications are still largely unknown.

\section{HSC niche}

The existence of a specialized niche or microenvironment that promotes HSCs maintenance was initially proposed in 1978 by Schofield et al. ${ }^{59}$ Already by this time, it was suggested that stem cells are seen in association with other fixed-tissue cells that prevent stem cell differentiation and ensure its continuous proliferation. However, only recently have advances been made to define their exact location as well as the molecular mechanisms by which they regulate HSCs. ${ }^{5,60,61}$

HSCs are mainly found in BM cavities in the trabecular region of long bones. Inside these cavities they are positioned at the interface of bone and BM, known as endosteum, in close proximity to bone-forming osteoblasts. ${ }^{62-64}$ A direct implication of osteoblasts in the regulation of HSCs was observed in studies in which an experimentally induced increase in the number of osteoblasts and trabecular bone area directly correlated with an increase in HSC pool size, but not in other hematopoietic cells in the BM. ${ }^{64,65}$ In agreement, depletion of osteoblasts in vivo was associated with reduced BM cellularity and extramedullary hematopoiesis. ${ }^{66}$ Furthermore, osteoblasts secrete factors that regulate HSC maintenance, such as angiopoietin, thrombopoietin and the chemokine Cxcl12. ${ }^{61}$ Despite these evidences, it still remains uncertain whether the endosteal interface represents a niche or if it only secretes factors that diffuse to nearby niches.

Besides the endosteal niche, a vascular niche in BM was also proposed upon observation of a large proportion of phenotypi- cally defined $\mathrm{CD} 150^{+}$HSCs attached to the endothelium of BM sinusoids. ${ }^{9}$ This idea is not unexpected, as both lineages share a common embryonic origin and during fetal development HSCs are maintained in niches that do not involve bone. Moreover, adult HSCs can also be found in extramedullary organs such as the spleen and the liver, and hematopoiesis can shift to these locations for long periods of time in the absence of an endosteal niche. Although stem cells seem to localize close to sinusoids in the spleen, ${ }^{9}$ these niches are still undefined, and non-vascular cells may also be essential to regulate HSC function in these locations. Similar to osteoblasts, perivascular cells also produce factors important for HSCs, such as Cxcl12. ${ }^{67}$ However, this dual niche hypothesis was recently challenged by new in vivo imaging techniques showing that osteoblasts and vasculature are in close proximity in the BM cavities, indicating that distinct endosteal and vascular niches are not anatomically feasible. ${ }^{68}$ In addition, the fact that osteoblast depletion results in extramedullary hematopoiesis ${ }^{66}$ suggests that a vascular niche alone is not sufficient to maintain hematopoiesis. Therefore, it is possible that rather than two different niches, vascular cells may have important roles in regulating HSCs near the osteoblasts, constituting a niche composed of different cell types. 5,61

\section{The stem-cell-niche synapse}

Many molecular and functional evidences suggest the existence of a complex molecular cross-talk between HSCs and the niche cells in their close vicinity, leading to the definition of one adhesion and signaling unit termed 'stem-cell-niche synapse', in analogy to the neuronal and immunological synapses. ${ }^{5} \mathrm{~A}$ wide variety of factors are involved in this synapse, and they mediate mainly two types of interactions. They promote adhesion between both cells and to the extracellular matrix, in order to maintain both cells in close proximity, and they promote activation of specific signaling pathways that influence HSC fate decisions, survival and proliferation. The activation of signaling pathways can be mediated by direct cell-cell interactions through binding of membrane-associated ligands and receptors, such as Notch signaling, or by binding of soluble factors to specific receptors located both on the HSC and on the niche cell, such as Wnt, Smad/TGF/BMP/Activin and Hedgehog signaling, and also hematopoietic cytokines like stem cell 
factor, which binds to the Kit receptor, and thrombopoietin, which binds to the $\mathrm{Mpl}$ receptor. ${ }^{5,60}$

Studies from many different laboratories implicated several evolutionarily conserved signaling pathways in the regulation of HSC function. All these pathways regulate important aspects during development and have been shown to be involved in cell-fate decisions and in the maintenance of stem cells in different tissues. These include the Wnt, Notch, Smad and Hedgehog pathways. Because of the highly redundant nature of these signaling routes and because of complex synergistic and antagonistic interactions between them and other signals, the precise function of these pathways has remained vague and frequently highly controversial. While generally in vitro assays and in vivo gain-of-function assays show that these pathways regulate HSC function, in vivo loss-of-function of key components of these pathways, such as $\beta$-Catenin (Wnt), Rbpj (Notch) and Smoothened (Hedgehog), suggests that none of these pathways is essential for HSC function. ${ }^{60,69-72}$ These issues will be further discussed in the subsequent articles of this series of spotlight reviews in Leukemia.

\section{Conflict of interest}

The authors declare no conflict of interest.

TC Luis ${ }^{1,2}$, NM-B Killmann ${ }^{3}$ and FJT Staal ${ }^{1,2}$ ${ }^{1}$ Department of Immunohematology and Blood Transfusion, Leiden University Medical Center, Leiden, The Netherlands; ${ }^{2}$ Department of Immunology, Erasmus MC, Erasmus University Medical Center, Rotterdam, The Netherlands and ${ }^{3}$ Leukemia Editorial Office, Leukemia - The Journal of Normal and Malignant Hemopoiesis, Paris, France E-mail: f.j.t.staal@lumc.nl

\section{References}

1 Metcalf D. Studies on colony formation in vitro by mouse bone marrow cells. II. Action of colony stimulating factor. J Cell Physiol 1970; 76: 89-99.

2 Moore MA, Metcalf D. Ontogeny of the haemopoietic system: yolk sac origin of in vivo and in vitro colony forming cells in the developing mouse embryo. Br J Haematol 1970; 18: 279-296.

3 Till JE, Mc CE. A direct measurement of the radiation sensitivity of normal mouse bone marrow cells. Radiat Res 1961; 14: 213-222.

4 Orkin SH. Diversification of haematopoietic stem cells to specific lineages. Nat Rev Genet 2000; 1: 57-64.

5 Wilson A, Trumpp A. Bone-marrow haematopoietic-stem-cell niches. Nat Rev Immunol 2006; 6: 93-106.

6 Okada S, Nakauchi H, Nagayoshi K, Nishikawa S, Miura Y, Suda T. In vivo and in vitro stem cell function of c-kit- and Sca-1positive murine hematopoietic cells. Blood 1992; 80: 3044-3050.

7 Spangrude GJ, Heimfeld S, Weissman IL. Purification and characterization of mouse hematopoietic stem cells. Science 1988; 241: 58-62.

8 Adolfsson J, Borge OJ, Bryder D, Theilgaard-Mönch K, AstrandGrundström I, Sitnicka E et al. Upregulation of Flt3 expression within the bone marrow $\operatorname{Lin}(-)$ Sca1 $(+)$ c-kit(+) stem cell compartment is accompanied by loss of self-renewal capacity. Immunity 2001; 15: 659-669.

9 Kiel MJ, Yilmaz OH, Iwashita T, Yilmaz OH, Terhorst C, Morrison SJ. SLAM family receptors distinguish hematopoietic stem and progenitor cells and reveal endothelial niches for stem cells Cell 2005; 121: 1109-1121.

10 Yang L, Bryder D, Adolfsson J, Nygren J, Månsson R, Sigvardsson $M$ et al. Identification of $\operatorname{Lin}(-)$ Sca1(+)kit(+)CD34(+) Flt3- short-term hematopoietic stem cells capable of rapidly reconstituting and rescuing myeloablated transplant recipients. Blood 2005; 105: 2717-2723.
11 Goodell MA, Brose K, Paradis G, Conner AS, Mulligan RC. Isolation and functional properties of murine hematopoietic stem cells that are replicating in vivo. J Exp Med 1996; 183: 1797-1806.

12 Bhatia M, Bonnet D, Kapp U, Wang JC, Murdoch B, Dick JE. Quantitative analysis reveals expansion of human hematopoietic repopulating cells after short-term ex vivo culture. J Exp Med 1997; 186: $619-624$

13 Conneally E, Cashman J, Petzer A, Eaves C. Expansion in vitro of transplantable human cord blood stem cells demonstrated using a quantitative assay of their lympho-myeloid repopulating activity in nonobese diabetic-scid/scid mice. Proc Natl Acad Sci USA 1997; 94: 9836-9841.

14 Ogawa M. Changing phenotypes of hematopoietic stem cells. Exp Hematol 2002; 30: 3-6.

15 Wilson A, Laurenti E, Trumpp A. Balancing dormant and self-renewing hematopoietic stem cells. Curr Opin Genet Dev 2009; 19: 461-468.

16 Knoblich JA. Mechanisms of asymmetric stem cell division. Cell 2008; 132: 583-597.

17 Brummendorf TH, Dragowska W, Zijlmans J, Thornbury G, Lansdorp PM. Asymmetric cell divisions sustain long-term hematopoiesis from single-sorted human fetal liver cells. J Exp Med 1998; 188: 1117-1124.

18 Takano H, Ema H, Sudo K, Nakauchi H. Asymmetric division and lineage commitment at the level of hematopoietic stem cells: inference from differentiation in daughter cell and granddaughter cell pairs. J Exp Med 2004; 199: 295-302.

19 Wu M, Kwon HY, Rattis F, Blum J, Zhao C, Ashkenazi R et al. Imaging hematopoietic precursor division in real time. Cell Stem Cell 2007; 1: 541-554.

20 Foudi A, Hochedlinger K, Van Buren D, Schindler JW, Jaenisch R, Carey $\mathrm{V}$ et al. Analysis of histone 2B-GFP retention reveals slowly cycling hematopoietic stem cells. Nat Biotechnol 2009; 27: 84-90.

21 Wilson A, Laurenti $\mathrm{E}$, Oser $\mathrm{G}$, van der Wath RC, Blanco-Bose W, Jaworski $M$ et al. Hematopoietic stem cells reversibly switch from dormancy to self-renewal during homeostasis and repair. Cell 2008; 135: 1118-1129.

22 Cumano A, Godin I. Ontogeny of the hematopoietic system. Annu Rev Immunol 2007; 25: 745-785.

23 Dzierzak E, Speck NA. Of lineage and legacy: the development of mammalian hematopoietic stem cells. Nat Immunol 2008; 9: 129-136.

24 Orkin SH, Zon LI. Hematopoiesis: an evolving paradigm for stem cell biology. Cell 2008; 132: 631-644.

25 Ferkowicz MJ, Starr M, Xie X, Li W, Johnson SA, Shelley WC et al. CD41 expression defines the onset of primitive and definitive hematopoiesis in the murine embryo. Development 2003; 130: 4393-4403.

26 Palis J, Robertson S, Kennedy M, Wall C, Keller G. Development of erythroid and myeloid progenitors in the yolk sac and embryo proper of the mouse. Development 1999; 126: 5073-5084.

27 Cumano A, Dieterlen-Lievre F, Godin I. Lymphoid potential, probed before circulation in mouse, is restricted to caudal intraembryonic splanchnopleura. Cell 1996; 86: 907-916.

28 Medvinsky A, Dzierzak E. Definitive hematopoiesis is autonomously initiated by the AGM region. Cell 1996; 86: 897-906.

29 de Bruijn MF, Ma X, Robin C, Ottersbach K, Sanchez MJ, Dzierzak E. Hematopoietic stem cells localize to the endothelial cell layer in the midgestation mouse aorta. Immunity 2002; 16: 673-683.

30 Bertrand JY, Chi NC, Santoso B, Teng S, Stainier DY, Traver D. Haematopoietic stem cells derive directly from aortic endothelium during development. Nature 2010; 464: 108-111.

31 Boisset JC, van Cappellen W, Andrieu-Soler C, Galjart N, Dzierzak $\mathrm{E}$, Robin C. In vivo imaging of haematopoietic cells emerging from the mouse aortic endothelium. Nature 2010; 464: 116-120.

32 Jaffredo T, Gautier R, Brajeul V, Dieterlen-Lievre F. Tracing the progeny of the aortic hemangioblast in the avian embryo. Dev Biol 2000; 224: 204-214.

33 Jaffredo T, Gautier R, Eichmann A, Dieterlen-Lievre F. Intraaortic hemopoietic cells are derived from endothelial cells during ontogeny. Development 1998; 125: 4575-4583.

34 Kissa K, Herbomel P. Blood stem cells emerge from aortic endothelium by a novel type of cell transition. Nature 2010; 464: 112-115. 
35 Bertrand JY, Giroux S, Golub R, Klaine M, Jalil A, Boucontet L et al. Characterization of purified intraembryonic hematopoietic stem cells as a tool to define their site of origin. Proc Natl Acad Sci USA 2005; 102: 134-139.

36 Gekas C, Dieterlen-Lievre F, Orkin SH, Mikkola HK. The placenta is a niche for hematopoietic stem cells. Dev Cell 2005; 8: $365-375$.

37 Kumaravelu P, Hook L, Morrison AM, Ure J, Zhao S, Zuyev S et al. Quantitative developmental anatomy of definitive haematopoietic stem cells/long-term repopulating units (HSC/RUs): role of the aorta-gonad-mesonephros (AGM) region and the yolk sac in colonisation of the mouse embryonic liver. Development 2002; 129: 4891-4899.

38 Ottersbach K, Dzierzak E. The murine placenta contains hematopoietic stem cells within the vascular labyrinth region. Dev Cell 2005; 8: 377-387.

39 Houssaint E. Differentiation of the mouse hepatic primordium. II. Extrinsic origin of the haemopoietic cell line. Cell Differ 1981; 10: 243-252.

40 Johnson GR, Moore MA. Role of stem cell migration in initiation of mouse foetal liver haemopoiesis. Nature 1975; 258: 726-728.

41 Dzierzak E. The emergence of definitive hematopoietic stem cells in the mammal. Curr Opin Hematol 2005; 12: 197-202.

42 Mikkola HK, Orkin SH. The journey of developing hematopoietic stem cells. Development 2006; 133: 3733-3744.

43 Ema H, Nakauchi H. Expansion of hematopoietic stem cells in the developing liver of a mouse embryo. Blood 2000; 95: 2284-2288.

44 Harrison DE, Zhong RK, Jordan CT, Lemischka IR, Astle CM. Relative to adult marrow, fetal liver repopulates nearly five times more effectively long-term than short-term. Exp Hematol 1997; 25: 293-297.

45 Morrison SJ, Hemmati HD, Wandycz AM, Weissman IL. The purification and characterization of fetal liver hematopoietic stem cells. Proc Natl Acad Sci USA 1995; 92: 10302-10306.

46 Rebel VI, Miller CL, Eaves CJ, Lansdorp PM. The repopulation potential of fetal liver hematopoietic stem cells in mice exceeds that of their liver adult bone marrow counterparts. Blood 1996; 87: 3500-3507.

47 Morrison SJ, Weissman IL. The long-term repopulating subset of hematopoietic stem cells is deterministic and isolatable by phenotype. Immunity 1994; 1: 661-673.

48 Jordan CT, McKearn JP, Lemischka IR. Cellular and developmental properties of fetal hematopoietic stem cells. Cell 1990; 61: 953-963.

49 Ikuta K, Kina T, MacNeil I, Uchida N, Peault B, Chien YH et al. A developmental switch in thymic lymphocyte maturation potential occurs at the level of hematopoietic stem cells. Cell 1990; 62: 863-874.

50 Hardy RR, Hayakawa K. A developmental switch in B lymphopoiesis. Proc Natl Acad Sci USA 1991; 88: 11550-11554.

51 Kantor AB, Stall AM, Adams S, Herzenberg LA, Herzenberg LA. Differential development of progenitor activity for three B-cell lineages. Proc Natl Acad Sci USA 1992; 89: 3320-3324.

52 Hock H, Hamblen MJ, Rooke HM, Schindler JW, Saleque S, Fujiwara $\mathrm{Y}$ et al. Gfi-1 restricts proliferation and preserves functional integrity of haematopoietic stem cells. Nature 2004; 431: 1002-1007.

53 Hock H, Meade E, Medeiros S, Schindler JW, Valk PJ, Fujiwara Y et al. Tel/Etv6 is an essential and selective regulator of adult hematopoietic stem cell survival. Genes Dev 2004; 18: 2336-2341.

54 Park IK, Qian D, Kiel M, Becker MW, Pihalja M, Weissman IL et al. Bmi-1 is required for maintenance of adult self-renewing haematopoietic stem cells. Nature 2003; 423: 302-305.

55 Kim I, Saunders TL, Morrison SJ. Sox17 dependence distinguishes the transcriptional regulation of fetal from adult hematopoietic stem cells. Cell 2007; 130: 470-483.

56 Ivanova NB, Dimos JT, Schaniel C, Hackney JA, Moore KA, Lemischka IR. A stem cell molecular signature. Science 2002; 298: 601-604.

57 Phillips RL, Ernst RE, Brunk B, Ivanova N, Mahan MA, Deanehan JK et al. The genetic program of hematopoietic stem cells. Science 2000; 288: 1635-1640.

58 Bowie MB, McKnight KD, Kent DG, McCaffrey L, Hoodless PA, Eaves CJ. Hematopoietic stem cells proliferate until after birth and show a reversible phase-specific engraftment defect. J Clin Invest 2006; 116: 2808-2816.

59 Schofield R. The relationship between the spleen colony-forming cell and the haemopoietic stem cell. Blood Cells 1978; 4: $7-25$.

60 Blank U, Karlsson G, Karlsson S. Signaling pathways governing stem-cell fate. Blood 2008; 111: 492-503.

61 Kiel MJ, Morrison SJ. Uncertainty in the niches that maintain haematopoietic stem cells. Nat Rev Immunol 2008; 8: 290-301.

62 Gong JK. Endosteal marrow: a rich source of hematopoietic stem cells. Science 1978; 199: 1443-1445.

63 Lord $\mathrm{BI}$, Testa NG, Hendry JH. The relative spatial distributions of CFUs and CFUc in the normal mouse femur. Blood 1975; 46: 65-72.

64 Zhang J, Niu C, Ye L, Huang H, He X, Tong WG et al. Identification of the haematopoietic stem cell niche and control of the niche size. Nature 2003; 425: 836-841.

65 Calvi LM, Adams GB, Weibrecht KW, Weber JM, Olson DP, Knight MC et al. Osteoblastic cells regulate the haematopoietic stem cell niche. Nature 2003; 425: 841-846.

66 Visnjic D, Kalajzic Z, Rowe DW, Katavic V, Lorenzo J, Aguila HL. Hematopoiesis is severely altered in mice with an induced osteoblast deficiency. Blood 2004; 103: 3258-3264.

67 Sugiyama T, Kohara H, Noda M, Nagasawa T. Maintenance of the hematopoietic stem cell pool by CXCL12-CXCR4 chemokine signaling in bone marrow stromal cell niches. Immunity 2006; 25: 977-988.

68 Lo Celso C, Fleming HE, Wu JW, Zhao CX, Miake-Lye S, Fujisaki J et al. Live-animal tracking of individual haematopoietic stem/progenitor cells in their niche. Nature 2009; 457: 92-96.

69 Gao J, Graves S, Koch U, Liu S, Jankovic V, Buonamici S et al. Hedgehog signaling is dispensable for adult hematopoietic stem cell function. Cell Stem Cell 2009; 4: 548-558.

70 Staal FJ, Luis TC, Tiemessen MM. WNT signalling in the immune system: WNT is spreading its wings. Nat Rev Immunol 2008; 8: 581-593.

71 Yuan JS, Kousis PC, Suliman S, Visan I, Guidos CJ. Functions of notch signaling in the immune system: consensus and controversies. Annu Rev Immunol 2010; 28: 343-365.

72 Luis T C, Weerkamp F, Naber BA, Baert MR, de Haas EF, Nikolic T et al. Wnt3a deficiency irreversibly impairs hematopoietic stem cell self-renewal and leads to defects in progenitor cell differentiation. Blood 2009; 113: 546-554. 